\title{
Erratum to: ApoSense: a novel technology for functional molecular imaging of cell death in models of acute renal tubular necrosis
}

\author{
Maya Damianovich • Ilan Ziv - Samuel N. Heyman - Seymour Rosen • Ahuva Shina • \\ Dvora Kidron • Tali Aloya • Hagit Grimberg • Galit Levin • Ayelet Reshef • \\ Alfonso Bentolila • Avi Cohen • Anat Shirvan
}

Published online: 8 October 2011

(C) Springer-Verlag 2011

Erratum to: Eur J Nucl Med Mol Imaging (2006) 33:281-291 DOI 10.1007/s00259-005-1905-x

The full and correct affiliations of the second author, Ilan Ziv, are as follows:

NeuroSurvival Technologies (NST) Ltd., 5 Odem St., Kiryat Matalon, Petah Tikva, 49170, Israel

Sackler School of Medicine, Tel Aviv University, Tel Aviv, Israel

Rabin Medical Center, Petach Tiqva, Israel

The online version of the original article can be found at http://dx.doi. org/10.1007/s00259-005-1905-x.
M. Damianovich $\cdot$ I. Ziv $(\bowtie) \cdot$ T. Aloya $\cdot$ H. Grimberg •
D. Kidron
Department of Pathology, Meir Hospital,
NeuroSurvival Technologies (NST) Ltd.,
Kfar-Saba, Israel
5 Odem St., Kiryat Matalon,
Petah Tikva 49170, Israel
e-mail: Ilan@aposense.com
S. N. Heyman · A. Shina
Department of Medicine, Hadassah Hospital,
Mt. Scopus and the Hebrew University Medical School,
Jerusalem, Israel
S. Rosen
Department of Pathology, Beth Israel Deaconess Medical
Center and Harvard Medical School,
I. Ziv
I. Ziv
Sackler School of Medicine, Tel Aviv University,
Tel Aviv, Israel
Boston, MA, USA
Rabin Medical Center,
Petach Tiqva, Israel 